\title{
MODELAGEM MATEMÁTICA E O ENSINO REMOTO NO CONTEXTO DA PANDEMIA
}

\section{MATHEMATICAL MODELING AND REMOTE THEACHING IN THE CONTEXT OF PANDEMIA}

\author{
Josiane Silva dos Reis ${ }^{1}$
}

\begin{abstract}
RESUMO
Diante da expansão e disseminação do coronavírus, professores e instituições de ensino, foram postos forçosamente em um cenário onde o ensino remoto se tornou emergente e, em alguns casos, obrigatório. Com isso, faz-se necessário buscar elaborar estratégias para identificar as reais necessidades dos estudantes para assim tentar dar continuidade as aulas nessa modalidade de ensino. Nessa perspectiva, este artigo tem como objetivo fazer uma análise sobre a viabilidade de se desenvolver remotamente uma atividade de modelagem matemática por meio de recursos suportados pelas tecnologias digitais de informação e comunicação. A atividade foi proposta e desenvolvida com uma turma do nono ano do ensino fundamental de uma escola pública da rede estadual de ensino no Estado do Pará e perseguiu os pressupostos teóricos de Burak (2004). Quanto a metodologia, trata-se de um estudo descritivo analítico, posto que buscou descrever e analisar o fenômeno observado. A abordagem é de cunho qualitativo, à medida que se aprofundou na compreensão das ações dos indivíduos e no que diz respeito aos procedimentos técnicos da pesquisa, trata-se de um estudo de caso, pois envolve a abordagem de conteúdo por intermédio do estudo de situações de contexto real. Esta, caracteriza-se por ser uma abordagem ativa e colaborativa, que promove o desenvolvimento da autonomia, quando conduzida de forma apropriada. As análises centraram-se em uma das temáticas propostas pela turma que apontou para o estudo de porcentagens e regra de três simples. Os resultados mostraram que é possível desenvolver remotamente propostas com o uso da modelagem matemática se considerarmos as condições mínimas necessárias de suporte tecnológico digital e planejamento didático.

Palavras-chave: Modelagem Matemática; Ensino Remoto; Tecnologias Digitais.
\end{abstract}

\begin{abstract}
Faced with the expansion and dissemination of the coronavirus, teachers and educational institutions were forcibly placed in a scenario where remote education has become emergent and, in some cases, mandatory. Thus, it is necessary to seek to develop strategies to identify the real needs of students in order to try to continue classes in this type of teaching. In this perspective, this article aims to analyze the feasibility of developing a mathematical modeling activity, remotely, through resources made available by digital information and communication technologies. The activity was proposed and developed with a class from the ninth grade of elementary school in a public school in the state education system in the State of Pará and followed the theoretical assumptions of Burak (2004). As for the methodology, it is a descriptive

\footnotetext{
${ }^{1}$ Mestra em Educação em Ciências e Matemáticas. Universidade Federal do Pará (UFPA). Professora Efetiva da Secretaria de Estado de Educação no Estado do Pará (SEDUC-PA). Belém. Pará. Brasil. Endereço: Avenida Rio Amazonas Quadra 55, Número 02, Bairro Maguari. Ananindeua Pará - Brasil. CEP: 67145-635. E-mail: professorajsr@gmail.com
}

(iD) ORCID iD: https://orcid.org/0000-0002-0376-2313. 
analytical study, since it sought to describe and analyze the observed phenomenon. The approach is of a qualitative, as it deepened in the understanding of the actions of individuals and with regard to the technical procedures of the research, it is a case study, as it involves the approach of content through the study of situations of real context. This is characterized by being an active and collaborative approach, which promotes the development of autonomy, when conducted properly. The analyzes focused on one of the themes proposed by the group that pointed to the study of percentages and simple rule of three. The results showed that it is possible to develop proposals remotely using mathematical modeling if we consider the minimum necessary conditions for digital technological support and didactic planning.

Keywords: Mathematical Modeling; Remote Teaching; Digital Technologies. 


\section{Introdução}

Nossa experiência, enquanto professores da educação básica, tem nos mostrado que a matemática, dentro das escolas, tem passado por momentos difíceis no que se refere ao nível de interesse por parte do corpo discente.

Neste trabalho defendemos a Modelagem Matemática como uma metodologia de ensino da matemática que tem entre seus objetivos reduzir os problemas de compreensão dos alunos em certos conteúdos matemáticos.

Reconhecemos que a Modelagem Matemática é concebida de distintas maneiras, sendo algumas denominações: alternativa pedagógica, ambiente de aprendizagem e metodologia de ensino. Estas concepções, ao menos no campo teórico, defendem um ensino de Matemática que seja mais crítico, humano, emancipador e que, de certa forma, venha para romper os modelos tradicionais, tão fortemente, enraizados em nossas escolas (BARBOSA, 2001; ALMEIDA, SILVA, VERTUAN, 2013; BURAK, 2004; 2010).

Nessa perspectiva, considerando o momento de crise que envolve a pandemia do coronavírus, o ensino remoto surge como um modelo de ensino emergente e deflagra uma série de desafios tanto para as escolas, professores e principalmente para os alunos.

Com o distanciamento social, fez-se necessário uma forçosa adaptação ao ensino remoto o que provocou mudanças em vários âmbitos do cenário educacional. O próprio Conselho Nacional de Educação (CNE), aprovou um parecer que possibilitou um cômputo de horas não presenciais para cumprir com a carga horária do ano letivo de 2020. O Ministério da Educação (MEC), com o objetivo de apoiar a universalização do acesso a internet e fomentar o uso pedagógico de tecnologias digitais na educação básica, criou o "Programa de Educação e Inovação Conectada" que teve a adesão de todas as 27 unidades federativas do país.

Porém, vale destacar que essa nova realidade também demonstrou fatos impactantes que ressaltaram a desigualdade em termos de uso da tecnologia. Segundo o Instituto de Pequisa Econômica Aplicada (IPEA), no Brasil, cerca de seis milhões de estudantes, desde a pré-escola até a pós-graduação, não têm acesso à internet banda larga ou 3G/4G em casa e, consequentemente, não conseguem participar do ensino remoto. Desses, 5,8 milhões são alunos de instituições públicas de ensino. É o que diz o estudo “Acesso Domiciliar à Internet e Ensino Remoto Durante a Pandemia", feito por esse instituto. Os alunos do ensino fundamental são os mais afetados. 
As soluções não são simples. No entanto, se vamos continuar com o ensino remoto, é necessário buscar meios mais efetivos de desenvolver metodologias que envolvem as ferramentas necessárias para tal.

Partindo destes princípios, este artigo tem por finalidade descrever e analisar uma atividade de modelagem matemática desenvolvida com o suporte do aplicativo de mensagem whatsapp $^{2}$. A pesquisa foi desenvolvida com uma turma do nono ano do ensino fundamental de uma escola pública em Belém no Estado do Pará e contemplou as cinco etapas do processo de modelagem propostos por Burak (2004).

Dentre os temas trabalhados durante o desenvolvimento da atividade, elegemos apenas um para descrição e análise nesta pesquisa por compreender sua relevância tanto com relação a aprendizagem do conteúdo matemático como sua relevância social, posto que surgiu apartir de uma necessidade financeira diretamente relacionada a pandemia.

\section{Modelagem Matemática e o ensino remoto}

As modificações provocadas na sociedade pelo uso das Tecnologias Digitais de Informação e Comunicação (TDIC's), são evidentemente irreversíveis. A relação dos nossos alunos com a internet é um interessante objeto de estudo. Grande parte dos que tem condições de acesso a rede, a utilizam massivamente para ler, conversar, assistir filmes, postar textos, imagens, vídeos entre outros.

Pensar em alunos que vivem imersos nessa rede, é reconhecer suas potencialidades de adquirir e produzir conhecimento, é enxergá-los como responsáveis pelo seu aprendizado considerando seus interesses, o que também é característica fundamental da modelagem matemática.

Existe possibilidades reais de aprendizagem quando o aluno se dedica à situações que são de sua realidade ou de seu interesse, grande parte das dificuldades na resolução de problemas enfrentados pelos estudantes é não encontrar sentido ou contexto sobre o que tentam solucionar.

Ao eleger o "interesse do aluno" como princípio, a Modelagem Matemática rompe com a forma usual de se deflagrar o processo de ensino utilizado na maioria das escolas.

\footnotetext{
${ }^{2}$ Aplicativo de mensagens e comunicação em áudio e vídeo pela internet disponível para smartphones Android, iOS, Windows phone, Nokia e computadores Mac e Windows.
} 
Burak (1992), afirma que a modelagem é "um conjunto de procedimentos cujo objetivo é construir um paralelo para tentar explicar matematicamente, os fenômenos presentes no cotidiano do ser humano, ajudando-o a fazer predições e tomar decisões" (BURAK, 1992, p. 62). Na perspectiva defendida por D’ambrósio (1986), “ Modelagem é um processo muito rico de encarar situações e culmina com a solução efetiva do problema real e não com a simples resolução formal de um problema artificial" (D’AMBRÓSIO, 1986, p. 11).

Para encaminhamento da prática com a Modelagem Matemática, Burak (2004), orienta que sejam consideradas cinco (5) etapas: I - Escolha do tema, um ou mais temas indicados pelos educandos; II - Pesquisa exploratória, desenvolvida pelos educandos sobre o tema e com mediação do educador; III - Levantamento dos problemas, estes que podem apresentar questões com conteúdos matemáticos ou outros que constituem o currículo escolar; IV - Resolução de problemas e o desenvolvimento da Matemática relacionada ao tema e; V - Análise crítica das soluções, que se caracteriza como um momento de discussões sobre o aprendido e até avaliação dos resultados obtidos.

Nessa abordagem, aprender torna-se uma atitude cuja competência precisa ser desenvolvida. A proatividade, a inventividade, a responsabilidade e o compromisso são condutas que precisam ser construídas e incentivadas. Isso é o que acontece também no ensino remoto, onde o estudante precisa ser continuamente incentivado e provocado para a aprendizagem.

Ensinar remotamente não significa ensinar à distância, embora esteja diretamente relacionado ao uso de tecnologia digital, o ensino remoto permite o uso de plataformas já existentes e abertas para outros fins, que não sejam exatamente educacionais. A diversidade dos recursos e das estratégias bem como das práticas são definidas a partir da familiaridade e da habilidade do professor em adotar tais recursos.

De acordo com Moreira e Schlemmer (2020, p. 08) o modelo de educação, chamado de "ensino remoto ou aula remota" é definido como "uma modalidade de ensino ou aula, que pressupõe o distanciamento geográfico de professores e estudantes [...]", busca suprir a emergência de falta de aulas presenciais, atendendo à necessidade do aluno, a fim de que se possa estudar e se manter ativo, mesmo estando o professor e o aluno cada um na sua casa. 
De acordo com Hodges (2020), o intuito do ensino remoto é ofertar um acesso temporário aos conteúdos curriculares que seriam desenvolvidos presencialmente; porém entendemos que as tecnologias digitais de informação e comunicação vem se ressignificando com o passar do tempo, ocupando cada vez mais um espaço importante nos processos de ensino e aprendizagem.

Cabe destacar que a incorporação das TDIC nas instituições escolares ainda é um entrave na realidade nacional; problemas de infraestrutura e de formação docente deficitária são variáveis importantes que interferem diretamente em uma utilização crítica, intencional e produtiva das tecnologias (BRAGA, 2018; THADEI, 2018).

Após essa breve contextualização temática e apresentação da concepção de Modelagem Matemática adotada, passamos para descrição da atividade e, posteriormente, uma apresentação de possíveis contribuições oportunizadas pelo trabalho do ensino remoto com a modelagem aos estudantes envolvidos.

\section{Processo metodológico}

Inicialmente, o planejamento didático da atividade considerava a utilização de outras plataformas digitais, além do whatsapp, porém após uma diagnose com o grupo de 36 alunos constatou-se que: dos 36 alunos; 9 tinham celular e internet 4G; 17 alunos tinham apenas celular sem acesso constante à internet; e 3 alunos tinham celular, computador e internet banda larga.

Verificamos a inviabilidade da utilização de outros recursos devido à limitação de acesso à internet e memória nos dipositivos eletrônicos dos alunos, por este motivo o grupo criado no whatsapp foi o nosso canal de comunicação e a ferramenta chave para o desenvolvimento da atividade.

Vale destacar que, dos 26 alunos que relataram ter celular, em realidade, 17 utilizavam o celular dos pais para fazerem as atividades, pesquisas e participar das aulas remotas . 7 não responderam nem interagiram no grupo até o encerramento do ano letivo, estes alunos acompanharam outras atividades como os compêndios impressos entregues na escola.

Esse diagnóstico apesar de ter alterado o planejamento inicial, não prejudicou o andamento da proposta, posto que o whatsapp atualmente possibilita a disponibilização de conteúdos no formato de áudio e video, como podcast e video-aulas; e permite aos 
seus usuários acessar salas virtuais onde podem ser criadas videoconferências acessíveis por link. Para Hodges (2020), o planejamento pedagógico em situações atípicas exige resolução criativa dos problemas, demandando transposição de ideias tradicionais e proposição de estratégias pedagógicas diferenciadas para atender à demanda dos estudantes e professores.

\section{Desenvolvimento da atividade com a modelagem}

A princípio, tudo era muito novo e o fato da não obrigatoriedade do cumprimento de um conteúdo programático nos deu liberdade para trabalhar com a modelagem sem preocupação com o tempo, um dos grandes desafios para o professor que se propõe a trabalhar com modelagem.

Em consonância com Burak (2004), a primeira etapa do processo de modelagem é a escolha do tema. Essa etapa é muito importante pois precisa considerar o interesse do aluno, segundo Bassanezi (2011, p. 46), “[...] dessa forma, se sentirão corresponsáveis pelo processo de aprendizagem, tornando sua participação mais efetiva" (BASSANEZI, 2011, p. 46).

Assim, com o objetivo de selecionar os temas para a atividade solicitei, no grupo do whatsapp, que os alunos relatassem suas rotinas no ensino remoto e sugerissem temas para serem estudados. Vale destacar que esses alunos já tinham realizado atividades de modelagem no ano letivo anterior, por este motivo já tinham ideia da proposta.

Com relação sobre suas rotinas no ensino remoto, os estudantes manifestaram inúmeros comentários, entre os tais, destaco os que estão relacionados a questões econômicas, pois tem relação direta com os impactos causados pela pandemia e estão dentro do contexto desta pesquisa:

“[...] quando tem internet eu assisto video aulas que os professores passam, quando não tem eu ajudo o papai na feira."

"[...] eu cuido dos meus irmãos pra mamãe poder trabalhar.”

“[...] meu pai tá sem trabalho aí eu tô fazendo bombons com a mamãe.”

“[...] eu uso o celular da mamãe pra ver as aulas ai quando ela sai pra trabalhar eu só vejo de noite o que teve de aula"

É claro que foram muitos os relatos dos alunos, alguns relataram não estar fazendo nada, outros disseram estar lendo os livros de história entre tantos outros. 
Vários temas foram propostos como; pandemia, dieta, zumbis, dança, futebol, moda, vendas, funk, política, entre outros. Além de sugirir um tema, os alunos tinham que relatar o por quê gostariam de estudar sobre ele.

Os alunos que sugeriram estudar sobre vendas, foram alunos que estavam passando por dificuldades financeiras na familia devido a pandemia e gostariam de ajudar os pais, por este motivo o grupo entendeu que isso seria mais importante naquele momento. Todo esse diálogo foi construido pelo grupo por meio de mensagens no grupo criado no whatsapp, entre aúdios e textos, o grupo chegou a um consenso.

A segunda etapa do processo de modelagem proposta por Burak (2004), é a pesquisa exploratória. A pesquisa exploratória se dá após a escolha do tema, conforme o tema escolhido, os alunos se organizam e estabelecem aspectos que gostariam de conhecer e estudar e partem, então, para a coleta de dados.

Definido o tema solicitei que os alunos pesquisassem sobre a temática e marcamos uma data para que eles falassem sobre suas pesquisas. Na data marcada, criamos uma sala virtual por meio do aplicativo whatsapp e o link foi compartilhado no grupo. Nem todos os alunos puderam participar, apesar disso foi um momento muito rico pois alguns expuseram seus interesses e até utilizaram o compartilhamento de tela ${ }^{3}$ para mostrar o que haviam pesquisado.

Foi dado um prazo para que os alunos que não participaram pudessem compartilhar no grupo as suas pesquisas. Após o período dado, alguns alunos não enviaram nada e alegaram não ter tido internet para fazer a pesquisa, outros enviaram videos, imagens e textos retirados de páginas na internet. Analisamos todo material compartilhado pelo grupo e organizamos dentro de eixos temáticos. As pesquisas com caracteristicas semelhantes foram utilizadas como critério para a formação de grupos que se dividiram entre cinco e seis alunos.

\footnotetext{
${ }^{3}$ É um recurso disponível em vários aplicativos, que permite compartilhar em tempo real textos e slides (entre outros), facilitando e aumentando a colaboração entre seus usuários.
} 
Quadro 1 - Tema e eixos temáticos.

\begin{tabular}{|c|c|c|}
\hline Tema & Eixos Temáticos & Pesquisa Exploratória \\
\hline \multirow{5}{*}{ Vendas } & Marketing & Sites e blogs (textos e vídeos) \\
\hline & Catálogos & Sites e blogs (imagens) e entrevista com feirantes \\
\hline & Propaganda & Sites e blogs (imagens) e panfletos \\
\hline & Chocolate & Sites e blogs (fotos e vídeos) \\
\hline & Vendas online & Sites e blogs (textos e vídeos) \\
\hline
\end{tabular}

Fonte: Elaborado pela autora.

Nesse momento da atividade, os alunos relataram muitas coisas no grupo e ficou inviável acompanhar, por este motivo decidimos criar um grupo no whatsapp para cada eixo temático. Os alunos demonstraram muito entusiasmo, autonomia e criatividade na busca por informações sobre o tema escolhido, tomaram caminhos não previstos e isso foi desafiador.

A informação mais encontrada nas pesquisas feitas por diferentes alunos foi o aumento considerável no número de vendas online devido ao fechamento de lojas, o que prejudicou muito a vida de quem não pode trabalhar de home office ${ }^{4}$ e deixou trabalhadores ainda mais expostos ao contágio do coronavírus. Isso gerou uma identificação nos alunos que acabaram enxergando seus familiares dentro desta estatística.

O alcance na pesquisa exploratória sobre o tema "vendas" foi muito vasto, o que deixaria este trabalho demasiadamente extenso, por este motivo, optamos por descrever e analisar apenas o eixo temático "Chocolate" composto por um grupo de cinco alunos.

Para preservar a identidade dos alunos, iremos nos referir a estes por A1, A2, A3, A4 e A5. Vale ressaltar que, a atividade realizada por este grupo se enquadra no contexto da pandemia do coronavírus, pois consideramos o fato de esses alunos estarem, de alguma forma, ajudando seus pais financeiramente devido os impactos provocados pela pandemia. Segundo Triviños (1987), a situação a ser estudada não pode ser isolada do seu contexto, pois o estudo de caso deve ser realizado com vistas a promover uma análise do contexto e dos processos envolvidos no fenômeno em estudo, considerando-se que o interesse do pesquisador deve ser com respeito à relação fenômeno-contexto. Os materiais coletados pelo grupo na pesquisa exploratória foram: imagens e videos com receitas de

\footnotetext{
${ }^{4}$ Home office é um termo emprestado do inglês, usado para descrever o trabalho realizado em casa.
} 
como fazer bombons de chocolate; e textos sobre vendas e custos retirados de sites e blogs da internet.

O levantamento de problemas é a terceira etapa do processo de modelagem. Nesta etapa os estudantes são incentivados a realização de conjecturas acerca das possíveis relações do tema com a matemática.

Com base no material coletado pelo grupo, foram levantados alguns problemas como, por exemplo:

\section{Quanto custa produzir um bombom de chocolate?}

2. O que significa um chocolate $70 \%$ cacau? Existem outras formas de representar esse número?

3. Se a mãe de $A 1$ gastou $R \$ 60,00$ com ingredientes, $R \$ 10,00$ com despesas gerais e $R \$ 20,00$ com embalagem para fazer 100 bombons, quanto esse bombom deve ser vendido para que ela tenha $100 \%$ de lucro?

É importante ressaltar que conforme Klüber (2010, p.158), na modelagem os problemas apresentam características distintas dos problemas apresentados pela maioria dos livros textos, assim: são elaborados a partir dos dados coletados na pesquisa exploratória; estimulam a busca e a organização dos dados; e favorecem a compreensão de uma determinada situação.

Com a exposição destes, partimos para a quarta etapa do processo de modelagem que é a resolução dos problemas e desenvolvimento da matemática relacionada ao tema. Trata-se de um momento bastante rico possibilitando que os conteúdos matemáticos ganhem importância e significado, bem como favorece a formação do pensamento matemático.

Nessa etapa, foi comum os alunos perguntarem se o que estavam respondendo estava correto. Nesse contexto, o professor tem o papel de orientador, auxiliando os estudantes no desenvolvimento das atividades, indicando possíveis caminhos a serem seguidos, “[...] tornando-o corresponsável pela aprendizagem e interessado pela matemática escolar” (QUARTIERI, 2012, p. 6). Para isso, segundo Almeida e Vertuan (2014, p.15), os educandos podem requerer o parecer do professor, “[...] não com a finalidade de sugerir ou indicar procedimentos, mas no sentido de opinar sobre e/ou 
validar seus procedimentos". Assim, nesta metodologia, percebe-se uma troca constante de ideias entre professor e aluno.

Com relação ao problema 1 , destacamos resposta da aluna A1:

“[...] Primeiro é preciso uma receita, depois fazer a lista dos ingredientes e o preço da embalagem, depois calcular quanto gastou em cada ingrediente por regra de 3 como no exemplo. [...] depois é só dividir o valor total que der pelo que render a receita, por exemplo se gastar 100 reais pra fazer a receita que rendeu 50 unidades, 100 dividido por 50 é igual a 2, ou seja, o seu custo será de 2 reais por unidade” (Fala transcrita de um áudio)

A aluna ainda comentou que viu exemplos parecidos na internet e no livro didático; e que perguntou à mae quanto ela pagava na barra de chocolate para montar seu próprio exemplo.

Figura 2 - Exemplo dado pela aluna A1.

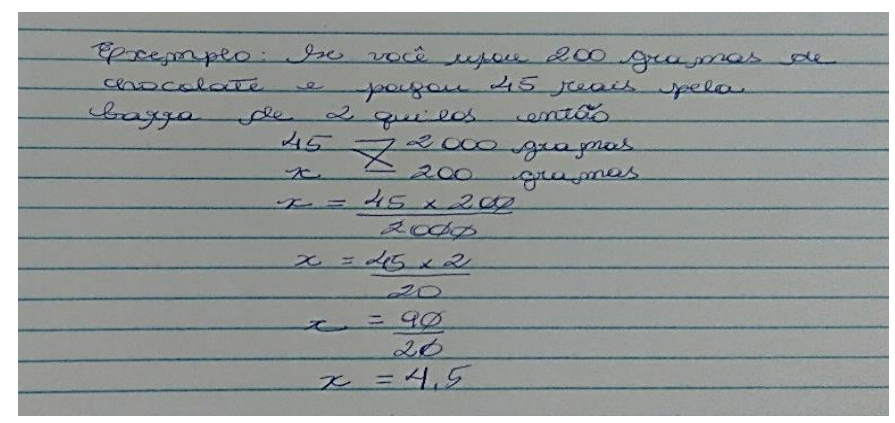

Fonte: A autora.

Alguns alunos não entenderam, então foi necessário explicar sobre a necessidade de se determinar o custo de cada ingrediente e por que a regra de três ajudava nesse cálculo.

Sobre o problema 2, os alunos se dispersaram um pouco e foram muitas os comentários sobre chocolate, abaixo destaco alguns que são mais pertinentes para análise.

"[...] Quanto maior a porcentagem mais amargo o chocolate é.” (A1)

“[...] Os 30\% é leite condensado e dos outros ingredientes.” (A4)

“[...] Eu li que esses são os melhores pra saúde.” (A3)

“[...] Eu achei uma lei que pra ser considerado chocolate tem que ter $25 \%$ de cacau.” (A2) 
“[...] 7 dividido por cem é a mesma coisa que 70\% e na calculadora aparece 0,07 que é a outra forma de escrever.” (A4)

"[...] Significa que a maior parte desse chocolate é composto por cacau” (A5)

No problema 3, destaco as respostas dos alunos A4 e A5:

“[...] tudo dá 90 reais, se tem 100 bombons é só dividir 90 por 100 igual a Al fez na primeira questão que dá 90 centavos. Pra pessoa ter $100 \%$ de lucro ela precisa vender pelo dobro, é só vender o bombom por 1,80 que é 90 centavos + 90 centavos." (A4)

“[...] tem que dividir o valor que ela gastou pela quantidade de bombom que deu pra fazer que dá 0,90 ai é só multiplicar por 2 que dá 1,80” (A5)

A análise crítica das soluções, quinta etapa do processo de modelagem, iniciou após a discussão sobre as soluções dadas aos problemas levantados. Trata-se de uma etapa que favorece o desenvolvimento do pensamento crítico e a argumentação lógica, bem como trata-se do momento em que se discute a coerência da solução dos problemas às situações da realidade estudada. Os alunos fizeram inferências válidas que representaram suas análises sobre os dados oriundos da pesquisa, utilizaram os objetos matemáticos adequados, como na aplicação da regra de três para exemplificar situações reais, e se mostraram envolvidos com os problemas, relataram que a atividade foi interessante porque, segundo A4, “[...]são coisas que acontecem de verdade.” Para Burak (1992), a modelagem matemática pode contribuir para criar nos alunos motivação e entusiasmo, não só pela matemática, mas pela escola de modo geral, à medida que substitui os conteúdos trabalhados linearmente, descontextualizados e fragmentados por uma prática crítica e reflexiva que considere o mundo real.

Os alunos também demonstraram sua compreensão em relação a porcentagem como parte e todo, sobre custo como gasto e lucro como ganho; e também sobre as diferentes representações de uma porcentagem. A3 ainda pesquisou e compartilhou no grupo os vários benefícios que os chocolates $70 \%$ cacau podem trazer para a saúde e comentou que iria mostrar para a professora de ciências.

$\mathrm{Na}$ modelagem, as relações entre a realidade e a matemática servem de subsídio para que conhecimentos matemáticos e não-matemáticos sejam acionados, produzidos e 
integrados. Neste sentido, a abordagem de questões reais pode motivar a compreensão de métodos e conteúdos da matemática escolar, contribuindo para a construção de conhecimentos e mostrando aplicações da Matemática em outras áreas do conhecimento (ALMEIDA; SILVA; VERTUAN, 2012).

Os alunos ainda fizeram comparações entre os preços dos chocolates, e compartilharam tipos de embalagens de baixo custo e sustentáveis que poderiam ser utilizadas na venda de bombons. Isso possibilitou conscientizar os alunos sobre a importância do uso de produtos recicláveis e seus benefícios para meio ambiente, fazendo-os refletir sobre o assunto.

Com a devida orientação, os alunos exploraram os conceitos matemáticos que foram necessários para que se realizasse a atividade e desenvolveram os conteúdos matemáticos necessários. Posteriormente, marcamos outra aula, via sala virtual no whatsapp, para que cada grupo pudesse apresentar sua atividade e expor suas impressões sobre a atividade.

\section{Algumas considerações}

Diante das grandes transformações sofridas em decorrências da pandemia do coronavírus, professores se viram diante de mudanças que impulsionaram o modo de planejar, desenvolver e avaliar suas atividades. O cenário é muito complexo, mas é urgentemente necessário que outras alternativas sejam propostas.

Na proposta deste trabalho, o uso de modelagem matemática no ensino remoto, os alunos apresentaram um comportamento de aprendizagem adequado com o descrito na literatura pertinente, saindo de mero espectador passivo a participante ativo no processo. A metodologia da modelagem se mostrou eficiente no que diz respeito à associação dos conteúdos curriculares com a matemática aplicada na vivência dos alunos.

Os entraves foram muitos, a falta de conexão de internet e também de equipamentos físicos, com o mínimo de suporte, afetaram um pouco o andamento da atividade, porém os alunos conseguiram alcançar significativamente os objetivos da atividade e, para além disso, relacionaram suas pesquisas com outras áreas do conhecimento consolidando conjecturas pertinentes sobre o assunto abordado.

Constatou-se que, utilizar a modelagem no ensino remoto, é uma ótima alternativa para: manter a concentração dos alunos, manter o estímulo cognitivo ativado, promover 
debates e informações para além dos componentes curriculares. É uma proposta válida e executável se considerarmos o mínimo de suporte físico e um planejamento didático adequado para sua concretização. Porém, é importante citar que a escola tem sua possibilidade de formação integral dos estudantes, e é indiscuível que isso aconteça de forma presencial.

\section{Referências}

ALMEIDA, Lourdes W.; SILVA, Karina P.; VERTUAN, Rodolfo E. Modelagem matemática na Educação Básica. 1. ed. São Paulo: Contexto, 2012.

ALMEIDA, L. M. W.; VERTUAN, R. E. Modelagem Matemática na Educação Matemática. In: ALMEIDA, L. M.W.; SILVA, K.A. P . (Orgs.). Modelagem Matemática em foco. Rio de Janeiro: Editora Ciência Moderna Ltda, 2014, p. 01-19.

BARBOSA, J. C. Modelagem Matemática: concepções e experiências de futuros professores. 2001. 194f. Tese (Doutorado em Educação Matemática) - Instituto de Geociências e Ciências Exatas, Universidade Estadual Paulista, Rio Claro, São Paulo, 2001. Disponível em:

https://www.periodicos.rc.biblioteca.unesp.br/index.php/bolema/article/view/10522/693 1 Acesso em: 30 dez. 2020.

BIEMBENGUT, Maria Salett; HEIN, Nelson. Modelagem matemática no ensino. $5^{\mathrm{a}}$. ed. São Paulo: Contexto, 2011.

BRAGA, R. Apresentação. In: FAUSTO, C.; DAROS, T. A sala de aula inovadora: estratégias pedagógicas para fomentar o aprendizado ativo. $1^{\mathrm{a}}$ ed. Porto Alegre: Penso, 2018.

BURAK, Dionísio. Modelagem Matemática e a sala de aula. In ENCONTRO

PARANAENSE DE MODELAGEM EM EDUCAÇÃO MATEMÁTICA, v. 01, 2004, p. 1 - 10. Disponível em:

https://www.yumpu.com/pt/document/view/12823736/modelagem-matematica-e-a-salade-aula-dionisio-burak-

BURAK, Dionísio. Modelagem Matemática: experiências vividas. Revista Analecta, Guarapuava, v.6, n.2, p. 33-48, 2005. Disponível em:

https://revistas.unicentro.br/index.php/analecta/article/view/2671. Acesso em: 05. Jan de 2021.

BURAK, Dionísio. Modelagem Matemática sob um olhar de Educação Matemática e suas implicações para a construção do conhecimento matemático em sala de aula.

Revista de Modelagem na Educação Matemática, Blumenau, v. 1, n. 1, p. 10-27, 2010. 


\section{IPEA - INSTITUTO DE PESQUISA ECONÔMICA APLICADA. Nota técnica.}

Acesso domiciliar à internet e ensino remoto durante a pandemia. Brasília: Ipea, n 88, 2020. Disponível em:

https://www.ipea.gov.br/portal/images/stories/PDFs/nota tecnica/200902 nt disoc n 8 8.pdf Acesso em: 22 de jan. 2021.

KLÜBER, Tiago Emanuel. Modelagem Matemática: revisitando aspectos que justificam a sua utilização no ensino. In: BRANDT, Célia Finck et alii. Modelagem matemática: uma perspectiva para a educação básica. Ponta Grossa: Editora UEPG, 2010.

MOREIRA, J. A.; SCHLEMMER, E. Por um novo conceito e paradigma de educação digital onlife. Revista UFG, v. 20, 2020.

QUARTIERI, M. T. A Modelagem Matemática na escola básica: a mobilização do interesse do aluno e o privilegiamento da matemática escolar. 2012. 199 f. Tese (doutorado) -Universidade do Vale do Rio dos Sinos, Programa de Pós-Graduação em Educação, São Leopoldo, 2012. Disponível em:

http://www.repositorio.jesuita.org.br/handle/UNISINOS/3063 . Acesso em: 05. jan de 2021.

TRIVIÑOS, A. N. Silva. Introdução à pesquisa em ciências sociais: A pesquisa qualitativa em educação. 1 ed. São Paulo: Atlas, 1987. 